\title{
Mathematics skills of Tswana-speaking learners in the North West Province of South Africa
}

\author{
J. G. Maree* and C. P. Erasmus \\ University of Pretoria, South Africa
}

*Corresponding author. Department of Curriculum Studies, Education Faculty, University of Pretoria, 0001 Pretoria, South Africa. Email: jgmaree@hakuna.up.ac.za.

\begin{abstract}
Inadequate achievement in mathematics frequently occurs especially amongst black learners, and the problem is assuming critical proportions. Tswana learners in the Mafikeng area find themselves in an educational situation that does not always promote optimal actualisation of their personal potential. One possible outcome of this situation is inadequate achievement in mathematics. The aim of this study is, inter alia, the exploration of the Tswana learner's inadequate achievement in mathematics in the Mafikeng area. This was done by administering a Diagnostic Test and a Learner's Questionnaire. The cognitive and affective facets of the Tswana learner's achievement in mathematics were measured. Our findings suggest that mathematics teaching can never be divorced from the socio-economic context in which it is taught.
\end{abstract}

\section{Introduction}

Learners throughout the country find themselves in situations in which high demands are made on them in order to process loads of information to master contents and to apply their knowledge and skills in everyday situations. South African training institutions are being challenged to assess whether they train learners sufficiently in survival skills, to become lifelong learners and to accept responsibility for the learning process. With an increased emphasis on the acquisition of certain outcomes and skills in an outcomes-based education system, it has become critically important for teachers to 
assess the effectiveness of their own teaching. The use of assessment instruments that could help teachers to monitor their own teaching is assuming increasing importance. Since the natural sciences currently are the focal point in education circles in South Africa, research with regard to instruments that deal with these subjects is of special importance (Department of Education, 1995).

Apart from the demands described above, the consequences of the former apartheid education system in South Africa are still 'catastrophic' (Kahn, 2004, p. 149) and they still seriously hamper the career prospects of (especially) black learners. The Third International Mathematics and Science Study Repeat Survey (TIMMS-R) of worldwide trends in respect of scholastic performance in mathematics and physical science (gateway subjects for tertiary education) confirmed once again that South African mathematics learners' performance was significantly poorer than that of the vast majority of other participating countries in the tests that measured basic mathematical skills (Howie, 2001, p. 18). South African learners struggled to deal with word problems and experienced great problems with fractions and sums in which geometry had to be used to calculate area. In general learners experienced huge problems communicating their answers in the language of the test (English) and they gave indications that they did not have the basic mathematical knowledge that is required from Grade 8 learners. Moreover recent research has revealed that the vast majority of Grade 6 learners in the Western Cape in South Africa (normally one of the top-achieving provinces in South Africa) have not even mastered the literacy and numeracy levels expected of Grade 4 learners (Kassiem, 2004). Of the approximately 35,000 Grade 6 learners tested in the Western Cape in 2003, only 15.6\% passed the numeracy test. Moreover the results confirmed the huge discrepancy between the achievements of former model C schools (with a predominantly white learnership) and those of previously disadvantaged schools (with a black learnership) (Dugmore in Kassiem, 2004). The influence of affective factors on mathematics performance has been noted by a number of authors (Maree, 1997a), who refer to the predictive value of affective factors relating to mathematics performance. Clearly inadequate performance in mathematics is seldom simply of a cognitive nature. Unless affective or emotional factors are taken into proper account, problems in mathematics may well be approached in a biased way. Thus it would be realistic to expect, at most, limited success in identifying and managing of inadequate performances in mathematics.

\section{Research aim}

The general aim of this study is to facilitate improved access of traditionally disadvantaged learners to good quality public education in South Africa. More specifically, its aim is inter alia to identify and narrow the gap between the Tswana learner's level of achievement in mathematics on the one hand, and his/her achievable levels in mathematics on the other hand.

\section{Research questions}

The main research question investigated in the current study concerns the specific training needs in mathematics of Tswana learners in Grades 3, 4 and 5 and can be 
phrased in the following terms: Does a significant relationship exist between the performance of the Grade 3, 4 and 5 Tswana learners in the Mafikeng area in mathematics diagnostic tests, and the self-confidence, study habits and study attitudes of these learners towards mathematics as measured by a Learner Questionnaire?

A number of secondary research questions that emerge from the primary research question include the following:

- Does a relationship exist between the Tswana learner's insight into language and problems in mathematics?

- Does a relationship exist between the Tswana learner's cognitive and affective disposition (self-confidence in mathematics, attitude and habits with regard to

In general, these questions centre around the associations between the performances of the different grade groups (Grades 3, 4 and 5); and the two sex groups in the diagnostic test (Mafikeng area) and the Learner Questionnaire. The following statistical procedures were, inter alia, carried out to investigate the hypothesis:

- Factor analysis;

- item analysis; and

- post hoc comparisons.

\section{Variables}

The variables used for the purpose of this survey were the following:

\section{Dependent variables}

Dependent variables concern Grade 3, 4 and 5 learners' performance in the subsections of the diagnostic tests, as well as in the three fields of the questionnaire (Mathematics Self-confidence, Study Attitude towards mathematics and 'Assistance' in mathematics.

Independent variables

The independent variables include the following: Grades (3, 4 and 5); and Sex.

\section{Definition of a number of key concepts}

\section{Tswana-speaking learner}

The concept 'Tswana learner' refers, inter alia, to the home language of the learner, namely Setswana. For the purpose of the current study this refers specifically to the learner who receives formal training in English, but whose home language is Setswana. 


\section{Research design}

The overall research design is multimethod, involving a combination of quantitative and qualitative methods. We chose an interpretative approach, implying that the aim was to understand epistemologically in a trustworthy way, but nonetheless accepting that researchers' perceptions of reality not only vary, but, in fact, differ greatly.

\section{Sampling}

The quota sampling method was used for the purpose of this study (Erasmus, 2002). The learners who participated in the sample had to meet the following requirements:

- They had to be attached to one of the four English-medium primary schools in the Molopo area in Mafikeng.

- The learner's home language had to be Setswana.

- Learners had to be in either Grades 3, 4 or 5.

Schools A, B and D that participated in the research were public schools, and the other was a private school. School $C$ was a traditionally white school in which the vast majority of learners were white. In the previous dispensation this school had fallen under the jurisdiction of the Cape Education Department, and afterwards had been taken over by the Bophuthatswana government. Schools A and D are schools that were founded by the former Bophuthatswana government. Their medium of teaching was English and they were regarded as semi-private schools. However, at present these two schools are ordinary state schools again. School B is a private school founded by the then Bophuthatswana government, and the primary school was founded in 1996. The majority of testees come from the lower economic income group. In most cases both parents work. There are also a considerable number of cases where the testees live with grandparents or other relatives.

For ethical reasons all learners (Setswana-speaking as well as other mother tongue speakers) in Grades 3, 4 and 5 took part in the survey, although only the data of the Tswana learners were used for the purpose of this survey.

Tables 1 and 2 set out the frequencies in terms of school, grade and sex of the Tswana learners who participated in the survey. Testing took place in February-March 2002.

Table 1. Frequencies in terms of school and grade

\begin{tabular}{|c|c|c|c|c|c|}
\hline & School A & School B & School C & School D & Total \\
\hline School & $\mathrm{N}$ & $\mathrm{N}$ & $\mathrm{N}$ & $\mathrm{N}$ & $\mathrm{N}$ \\
\hline Grade 3 & 127 & - & 9 & 95 & 231 \\
\hline Grade 4 & 74 & 11 & 28 & 109 & 222 \\
\hline Grade 5 & 80 & 9 & 33 & 107 & 229 \\
\hline TOTAL & 281 & 20 & 70 & 311 & 682 \\
\hline Percentage & $41.2 \%$ & $2.9 \%$ & $10.3 \%$ & $45.6 \%$ & 100 \\
\hline
\end{tabular}


openUP (July 2007)

Table 2. Frequencies in terms of grade and sex

\begin{tabular}{|c|c|c|c|c|}
\hline & Grade 3 & Grade 4 & Grade 5 & Total \\
\hline & $\mathrm{N}$ & $\mathrm{N}$ & $\mathrm{N}$ & $\mathrm{N}$ \\
\hline Boys & 113 & 109 & 100 & 322 \\
\hline Girls & 114 & 113 & 128 & 355 \\
\hline Total & 227 & 222 & 228 & 677 \\
\hline
\end{tabular}

\section{Measuring instruments}

\section{Learner questionnaire}

A questionnaire containing 50 items was initially compiled for the Tswana-speaking learners (Erasmus, 2002). The items in this Learner Questionnaire were, inter alia, based on items of the Study Orientation Questionnaire in Mathematics (Maree, 1997b).

Certain factors that were taken into account in compiling the final set of questions, include the following:

- The learners are all attached to primary schools, and their experience of the training and learning situation in mathematics differs from that of learners in the high school.

- The contents of the items and the words used in them, should be on such a level that they can be understood by all Tswana-speaking testees.

- The overall aim of the Learner Questionnaire is to determine whether the following factors do indeed play a role in the mathematics performance of the Tswana learner:

- Aid in mathematics.

- Mathematics self-confidence.

- Study attitude towards mathematics.

\section{Diagnostic tests}

The diagnostic tests implemented in the current study are based on diagnostic tests for mathematics constructed by the University of Stellenbosch (author and date of publication unknown). The language and items were, however, adapted for the learners who are taught through medium of a second language (Erasmus, 2002).

The diagnostic test was submitted to the teachers of the participating schools with a view to their evaluation of the items in order to facilitate content validity. For the purpose of the current study this test will be called the Mafikeng Diagnostic Test. The test was in English and comprised five subsections.

(1) Mental arithmetic-No language. In this section the learner was only required to 'read' sums. Comprehension of the problem did not depend on language. Examples of items under this section are:

$$
3+5=\ldots \text {; } 6 \times 7=
$$


(2) Mental arithmetic-Language. The learner's comprehension of the problem depended on his/her comprehension of the language and, specifically, on his/her mathematics vocabulary. Examples of items in this section include the following:

'What is 5 less than 100?'

'What is the difference between 12 and 21?'

(3) Mechanical operations. This section also tested only the learner's mathematical abilities. Six items tested the four basic main operations, for example:

$204+96+303=$ ; $805-368=$ ; $30 \times 33=$

(4) Word sums. The word sum tests both the learner's 'reading comprehension' and mathematical abilities. An example of this type of item is:

'One slab of chocolate weighs 200g. How much will 4 slabs of chocolate weigh?'

(5) Notation and place value. Language also plays an important role in this subsection. Items include the following:

'Arrange the following numbers from big to small; 7219; 9127; 1297; 1792; 2197.'

'How many hundreds in the number 5302?'

The diagnostic tests for the different grades contain the same subsections and types of items, but they differ in respect of degrees of difficulty.

\section{Limitations of the research}

The following are a number of the limitations of the study:

- The study was limited in scope.

- Previously standardised questionnaires were not used in the research.

- The group was limited and the possibility of statistical inference or generalisation was also limited.

- A different researcher may well interpret the results in a different way.

\section{Ethical aspects}

Liaison with the Education Department and the school principals, as well as with parents of the Tswana learners, had taken place before the research was implemented. The District Manager of the North West Department of Education, as well as the Executive Manager of the private school gave written permission for the current research to be carried out. Parents were informed of the research project and, where possible, requested to allow the publication of the research results.

\section{Data processing, procedure and instruments}

In an effort to determine whether there was a significant relationship between the performance of Tswana learners of the Mafikeng area in mathematics diagnostic tests 
and their achievement in a study orientation questionnaire in mathematics, the following procedure was followed:

- The total group's frequency distribution with regard to grade and sex was determined.

- The diagnostic tests' frequency distribution was established.

- The mean and standard deviation of the diagnostic tests were calculated.

- The frequency distribution of the questionnaire was determined for each separate grade.

- The following statistical procedures were carried out to investigate the stated hypotheses.

(a) A factor analysis (Varimax rotation) was carried out on the items of the questionnaire to investigate the underlying pattern or associations for a large number of variables.

(b) An item analysis was carried out on the questionnaire completed by the learners.

(c) The Wilcoxon Rank Sum Test and the Kruskal-Wallis procedure were carried out to further investigate the differences between the medians of the respective variables. The Wilcoxon Rank Sum Test was used to compare the performances of the boys and girls (the sexes) in the Mathematics Diagnostic Test (Mafikeng area) with one another. By means of the Kruskal-Wallis procedure a comparison was drawn between the three different grade groups' performance in the Mathematics Diagnostic Test (Mafikeng area).

(d) Reliability coefficient: Cronbach's alpha coefficient was calculated for the questionnaire on the basis of the totals for Grades 3, 4 and 5 in respect of the three fields of the Learner Questionnaire. 


\section{Hypotheses}

The following four statistical hypotheses were investigated:

$\mathrm{H}_{01}: \eta_{\text {boys }}=\eta_{\text {girls }}$

The medians of the boys and girls in the Mathematics Diagnostic Test are the same. (OR: There are no differences between the medians of boys and girls in the Mathematics Diagnostic Test.)

$\mathrm{H}_{\mathrm{a} 1}: \eta_{\text {boys }} \neq \eta_{\text {girls }}$ The medians of boys and girls in the Mathematics Diagnostic Test are not the same. (OR: There is a significant difference between the medians of boys and girls in the Mathematics Diagnostic Test.)

$\mathrm{H}_{02}: \eta_{\text {boys }}=\eta_{\text {girls }}$

The medians of boys and girls in the Learner Questionnaire are the same. (OR:

There are no differences between the medians of boys and girls in the Learner Questionnaire.)

$\mathrm{H}_{\mathrm{a} 2}: \eta_{\text {boys }} \neq \eta_{\text {girls }}$

The medians of boys and girls in the Learner Questionnaire are not the same. (OR: There is a significant difference between the medians of boys and of girls in the Learner Questionnaire.)

$\mathrm{H}_{03}: \eta_{\text {Grade3 }}=\eta_{\text {Grade } 4}=\eta_{\text {Grade } 5}$

The medians of the different grade groups in the Mathematics Diagnostic Test are the same. (OR: There are no differences between the medians of the different grade groups in the Mathematics Diagnostic Test.)

$\mathrm{H}_{\mathrm{a} 3}: \eta_{\text {Grade3 }} \neq \eta_{\text {Grade } 4} \neq \eta_{\text {Grade5 }}$

The medians of at least one grade group in the Mathematics Diagnostic Test differ significantly from those of the other grade groups.

$\mathrm{H}_{04}: \eta_{\text {Grade3 }}=\eta_{\text {Grade } 4}=\eta_{\text {Grade } 5}$

The medians of the different grade groups in the Learner Questionnaire are the same. (OR: There are no differences between the medians of the different grade groups in the Learner Questionnaire.)

$\mathrm{H}_{\mathrm{a} 4}: \eta_{\text {Grade } 3} \neq \eta_{\text {Grade } 4} \neq \eta_{\text {Grade } 5}$

At least one grade group's medians differ significantly from those of the other groups.

\section{Results}

All the eigen values are larger than one and can therefore be interpreted. Furthermore it is clear from Table 3 that all 30 selected items belong to the three fields: the criterion used to determine whether items should be included in the questionnaire, is Child's arbitrary criterion of 0.30 in respect of factor loadings (Child, 1990).

The reliability of the three fields of the Learner Questionnaire was determined with the help of Cronbach's alpha coefficient. 
The reliability coefficient (Table 4) for the Learner Questionnaire lies between 0.52 and 0.74 and may be regarded as highly satisfactory for the purpose of this questionnaire.

\section{Intercorrelations between fields}

The intercorrelations of the fields of the Learner Questionnaire (Mathematics selfconfidence, Attitude and Assistance) for the total group (Grades 3, 4 and 5) are indicated in Table 9.

It appears from Table 9 that the intercorrelations between the three fields vary between 0.073 and 0.406 . There is a higher correlation between Field 1 (Mathematics self-confidence) and Field 2 (Attitude) than between Fields 1 (Mathematics selfconfidence) and 3 (Assistance) or than Fields 2 (Attitude) and 3 (Assistance).

\section{Qualitative data}

In-depth interviews were held with both learners and teachers in an attempt to clarify certain responses and to identify patterns that had emerged from the data. Some of the patterns that emerged from the data are shown and discussed below. 
openUP (July 2007)

Table 3. Final factor loading on the Learner Questionnaire-total group (Grades 3,4 and 5)

\begin{tabular}{|c|c|c|c|}
\hline $\begin{array}{l}\text { Item number: Original } \\
\text { questionnaire }\end{array}$ & $\begin{array}{l}\text { Field } 1 \text { Mathematics } \\
\text { self-confidence }\end{array}$ & $\begin{array}{l}\text { Field } 2 \\
\text { Attitude }\end{array}$ & $\begin{array}{c}\text { Field } 3 \\
\text { Assistance }\end{array}$ \\
\hline VB28 & 0.59379 & 0.06628 & 0.18745 \\
\hline VB26 & 0.52489 & 0.23145 & -0.02064 \\
\hline $\mathrm{VB} 25$ & 0.51271 & -0.03737 & -0.08464 \\
\hline VB29 & 0.50076 & 0.25387 & -0.00394 \\
\hline $\mathrm{VB} 24$ & 0.48960 & -0.11089 & 0.17346 \\
\hline $\mathrm{VB} 23$ & 0.48407 & 0.19589 & -0.27778 \\
\hline VB30 & 0.48000 & 0.02904 & -0.13842 \\
\hline VB33 & 0.47709 & 0.26112 & 0.16148 \\
\hline VB22 & 0.46035 & -0.04107 & 0.08105 \\
\hline VB34 & 0.46005 & 0.07618 & -0.08859 \\
\hline $\mathrm{VB} 21$ & 0.45179 & 0.26986 & -0.14204 \\
\hline VB32 & 0.41663 & 0.17290 & 0.25618 \\
\hline $\mathrm{VB} 27$ & 0.36972 & 0.18726 & -0.09143 \\
\hline VB 14 & 0.03525 & 0.62308 & -1.10121 \\
\hline $\mathrm{VB} 2$ & 0.00571 & 0.59049 & 0.23919 \\
\hline VB5 & 0.04401 & 0.56491 & -0.09375 \\
\hline VB 17 & 0.18822 & 0.54764 & -0.01230 \\
\hline VB19 & 0.10912 & 0.50547 & -0.13158 \\
\hline VB9 & 0.14111 & 0.46632 & 0.09064 \\
\hline VB16 & 0.11283 & 0.44091 & 0.16355 \\
\hline VB3 & 0.09574 & 0.42432 & -0.04528 \\
\hline VB4 & -0.05649 & 0.40317 & 0.03212 \\
\hline VB7 & 0.24075 & 0.38995 & 0.04277 \\
\hline VB 10 & 0.25822 & 0.32964 & 0.25813 \\
\hline VB6 & -0.11996 & 0.06842 & 0.57641 \\
\hline VB15 & 0.04460 & -0.03888 & 0.49255 \\
\hline VB11 & 0.08389 & 0.34852 & 0.44779 \\
\hline VB13 & -0.05465 & -0.04790 & 0.43151 \\
\hline VB18 & -0.08226 & -0.07639 & 0.40770 \\
\hline VB8 & 0.22621 & 0.16764 & 0.38236 \\
\hline Eigen values & 4.5994 & 2.0080 & 1.6754 \\
\hline Percentage variation explained & 3.326 & 3.179 & 1.778 \\
\hline
\end{tabular}


Inspection of Table 10 suggests that the majority of the learners in all grade groups enjoy mathematics. Learners in higher grades seem to enjoy the subject even more than those in lower grades. The table provides some proof that learners experience difficulty with the language in which mathematics is taught at this level

Table 4. Cronbach's alpha ( $\alpha$ ) coefficient: Learner Questionnaire (total group)

\begin{tabular}{lccc}
\hline Scale & 1-Mathematics self-confidence & 2-Attitude & 3-Assistance \\
\hline Alpha & 0.743 & 0.725 & 0.517 \\
\hline
\end{tabular}

Table 5. Diagnostic Test-Comparison of sexes by means of Wilcoxon Rank Sum Test $(n=674)$

\begin{tabular}{|c|c|c|c|c|c|c|c|}
\hline \multirow[b]{3}{*}{ Diagnostic Test Subsections } & \multicolumn{6}{|c|}{ Sex } & \multirow[b]{3}{*}{$\mathrm{p}$ values } \\
\hline & \multicolumn{3}{|c|}{ Girls $(n=320)$} & \multicolumn{3}{|c|}{ Boys $(n=317)$} & \\
\hline & M & Sd & $\mathrm{Me}$ & M & Sd & $\mathrm{Me}$ & \\
\hline Q1: Mental arithmetic (No Language) & 73.7 & 22.3 & 80.0 & 74.8 & 21.4 & 80.0 & 0.59 \\
\hline Q2: Mental arithmetic (Language) & 59.9 & 26.4 & 62.5 & 58.2 & 26.0 & 62.5 & 0.32 \\
\hline Q3: Mechanical Operation (No Language) & 46.7 & 29.5 & 50.0 & 43.3 & 29.3 & 41.7 & 0.1 \\
\hline Q4: Notation and Place value (Language) & 55.6 & 25.6 & 58.8 & 53.2 & 25.8 & 53.8 & 0.26 \\
\hline Q5: Word sums (Language) & 45.7 & 26.1 & 46.7 & 39.0 & 25.8 & 40.0 & $0.001^{\star}$ \\
\hline Q6: TOTAL: & 54.8 & 20.6 & 55.8 & 51.6 & 19.9 & 52.0 & 0.0553 \\
\hline
\end{tabular}

* Significant on the $5 \%$ level of significance.

N for Q1-Q4: Boys 320, Girls 354 .

$\mathrm{N}$ for Q5 and Q6: Boys 320, Girls 352. 
(i.e. English). Clearly almost half the learners in the research group experience difficulty in understanding the specific, technical language of mathematics, even at this early stage of their careers. Moreover the table also reveals that the majority of learners believe that they can do better in mathematics. During interviews, learners confirmed this view, stating that they would do better if a number of debilitating factors were handled in a satisfactory way. These include language of learning (learners are taught in English, however, very few of them have mastered English properly), a general poor socio-economic environment, overfull classrooms, and lack of learner support material.

The number of Grade 4 learners who become anxious when they do mathematics is the highest of the three groups. During interviews learners confirmed their frustration at the fact that teachers and other adults seem to become irritated when learners ask questions in the mathematics class.

Table 6. Fields of the Learner Questionnaire: Results of the Wilcoxon Rank Sum Test for the comparison of sexes $(\mathrm{N}=656)$

\begin{tabular}{|c|c|c|c|c|c|c|c|}
\hline \multirow[b]{3}{*}{ Fields } & \multicolumn{6}{|c|}{ Sex } & \multirow[b]{3}{*}{$\mathrm{p}$ values } \\
\hline & \multicolumn{3}{|c|}{ Girls $N=317$} & \multicolumn{3}{|c|}{ Boys $\mathrm{N}=339$} & \\
\hline & M & Sd & $\mathrm{Me}$ & M & Sd & $\mathrm{Me}$ & \\
\hline Field 1: Mathematics self-confidence & 1.630 & 0.240 & 1.700 & 1.668 & 0.222 & 1.692 & $0.0493^{\star}$ \\
\hline Field 2: Attitude & 1.707 & 0.236 & 1.727 & 1.715 & 0.217 & 1.727 & 0.9543 \\
\hline Field 3: Assistance & 1.816 & 0.219 & 1.833 & 1.824 & 0.192 & 1.833 & 0.7946 \\
\hline
\end{tabular}

*Significant on the $5 \%$ level of significance. 
Table 7. Diagnostic Test-(Mafikeng area) Results of the Kruskal-Wallis procedure for the comparison of the three different grade groups by means of the Mathematics Diagnostic Test

\begin{tabular}{|c|c|c|c|c|c|c|c|c|c|c|}
\hline \multirow[b]{3}{*}{$\begin{array}{l}\text { Diagnostic Test } \\
\text { Subsections }\end{array}$} & \multicolumn{9}{|c|}{ GRADE } & \multirow[b]{3}{*}{$P$ values } \\
\hline & \multicolumn{3}{|c|}{$3 \mathrm{~N}=230$} & \multicolumn{3}{|c|}{$4 \mathrm{~N}=219$} & \multicolumn{3}{|c|}{$5 \mathrm{~N}=230$} & \\
\hline & M & Sd & $\mathrm{Me}$ & M & Sd & $\mathrm{Me}$ & M & Sd & $\mathrm{Me}$ & \\
\hline $\begin{array}{l}\text { Q1: Mental arithmetic } \\
\text { (No language) }\end{array}$ & 75.3 & 16.3 & 75.0 (a) & 71.1 & 27.0 & 80.0 (a) & 75.7 & 21.2 & 85.7 (a) & 0.178 \\
\hline $\begin{array}{l}\text { Q2: Mental arithmetic } \\
\text { (Language) }\end{array}$ & 65.9 & 25.8 & 75.0 (a) & 49.6 & 25.8 & 45.5 (b) & 61.4 & 24.5 & 66.7 (a) & $0.0000^{\star}$ \\
\hline $\begin{array}{l}\text { Q3: Mechanical } \\
\text { Operation (No } \\
\text { Language) }\end{array}$ & 54.0 & 31.9 & 58.3 (a) & 35.7 & 28.0 & 33.3 (b) & 45.2 & 25.2 & $50.0(\mathrm{c})$ & $0.0000^{\star}$ \\
\hline $\begin{array}{l}\text { Q4: Notation and } \\
\text { Place value } \\
\text { (Language) }\end{array}$ & 57.9 & 25.6 & 58.8 (a) & 58.7 & 25.4 & 63.6 (a) & 46.8 & 24.5 & 46.2 (b) & $0.0000^{*}$ \\
\hline $\begin{array}{l}\text { Q5: Word sums } \\
\text { (Language) }\end{array}$ & 47.7 & 27.3 & 46.7 (a) & 39.2 & 26.1 & 33.3 (b) & 40.7 & 24.4 & 41.2 (b) & $0.0000^{\star}$ \\
\hline Q6: TOTAL & 59.4 & 19.9 & 62.1 (a) & 48.9 & 19.8 & 47.9 (b) & 51.2 & 19.8 & $50.0(b)$ & $0.0000^{\star}$ \\
\hline
\end{tabular}

* Significant on the $5 \%$ level of significance.

a, b, c: Medians with common characters do not differ significantly (inter pret row by row).

Table 8. Results of the Kruskal-Wallis procedure for the comparison of the three different grade groups by means of the fields as obtained through factor analysis $(\mathrm{N}=656)$

\begin{tabular}{|c|c|c|c|c|c|c|c|c|c|c|}
\hline \multirow[b]{3}{*}{ Fields } & \multicolumn{9}{|c|}{ Grade } & \multirow[b]{3}{*}{$\mathrm{p}$ values } \\
\hline & \multicolumn{3}{|c|}{$3 \mathrm{~N}=221$} & \multicolumn{3}{|c|}{$4 \mathrm{~N}=219$} & \multicolumn{3}{|c|}{$5 \mathrm{~N}=216$} & \\
\hline & $\mathrm{M}$ & Sd & $\mathrm{Me}$ & M & Sd & $\mathrm{Me}$ & M & Sd & $\mathrm{Me}$ & \\
\hline $\begin{array}{l}\text { Mathematics } \\
\text { self-confidence }\end{array}$ & 1.629 & 0.235 & $\begin{array}{l}1.667 \\
\text { (a) }\end{array}$ & 1.604 & 0.229 & $\begin{array}{l}1.615 \\
\text { (a) }\end{array}$ & 1.719 & 0.214 & $\begin{array}{l}1.769 \\
\text { (b) }\end{array}$ & $0.000^{\star}$ \\
\hline Attitude & 1.675 & 0.263 & $\begin{array}{l}1.727 \\
\text { (a) }\end{array}$ & 1.678 & 0.218 & $\begin{array}{l}1.720 \\
\text { (a) }\end{array}$ & 1.785 & 0.169 & $\begin{array}{l}1.818 \\
\text { (b) }\end{array}$ & $0.000^{\star}$ \\
\hline Assistance & 1.778 & 0.248 & $\begin{array}{l}1.833 \\
\text { (a) }\end{array}$ & 1.835 & 0.175 & $\begin{array}{l}1.833 \\
(a b)\end{array}$ & 1.849 & 0.177 & $\begin{array}{l}1.833 \\
\text { (b) }\end{array}$ & $0.028^{\star}$ \\
\hline
\end{tabular}

* Significant on the $5 \%$ level of significance.

$\mathrm{a}, \mathrm{b}, \mathrm{c}$ : Medians with common characters do not differ significantly (interpret row by row). 
openUP (July 2007)

Table 9. Intercorrelations of the fields of the Learner Questionnaire for the total group (Grades 3,4 and 5 )

1-Mathematics self-confidence 2-Attitude 3-Assistance

1-Mathematics-self-confidence

2-Attitude 0.406

3-Assistance $\quad 0.073 \quad 0.285$

\section{Discussion}

\section{Evaluation of the Learner Questionnaire}

The factor analysis and item analysis highlighted three clear fields for the total group (i.e. Grades 3, 4 and 5) (Table 3), namely

- mathematics self-confidence;

- attitude (towards mathematics); and

- assistance. (The effect of assistance in a group or in an individual context on the learner's motivation to do better in mathematics.)

\section{Post hoc comparisons}

The Wilcoxon Rank Sum Test (Table 5) revealed statistically significant differences between the medians of the boys and girls in respect of the subsection Word sums of the Diagnostic Test (Mafikeng area). The Tswana girls performed significantly better in the subsection Word sums (Q5) than did the Tswana boys.

Table 10. Frequency table of a number of items in the Learner Questionnaire

\begin{tabular}{lcc}
\hline Grade 3 & Grade 4 & Grade 5 \\
\hline $\begin{array}{l}\text { Item 1: I enjoy mathematics } \\
81 \%\end{array}$ & $89 \%$ & $95 \%$ \\
$\begin{array}{l}\text { Item 11: I understand maths better when someone explains it in Setswana } \\
57 \%\end{array}$ & $58 \%$ & $39 \%$ \\
$\begin{array}{l}\text { Item 17: I can do word problems only if someone explains them to me } \\
82 \%\end{array}$ & $90 \%$ & $86 \%$ \\
$\begin{array}{l}\text { Item 18: I understand the words used in maths } \\
52 \%\end{array}$ & $51 \%$ & $50 \%$ \\
$\begin{array}{l}\text { Item 19: I can do better in mathematics } \\
73 \%\end{array}$ & $80 \%$ & $85 \%$ \\
$\begin{array}{l}\text { Item 26: I become anxious when I do mathematics } \\
34 \%\end{array}$ & $58 \%$ & $40 \%$ \\
$\begin{array}{l}\text { Item 29: The adults who help me become irritated when I don't understand } \\
43 \%\end{array}$ & $42 \%$ & $40 \%$ \\
\hline
\end{tabular}


Inspection of the results of the Wilcoxon Rank Sum Test (Table 6) showed that the performance of boys and girls in Field 1 (Mathematics self-confidence) differed significantly. Boys performed statistically significantly better in this field than girls.

Inspection of the results of the Kruskal-Wallis procedure (Table 8) also highlighted significant differences in the medians of Grade 3,4 and 5 learners in respect of all three fields of the Learner Questionnaire. The medians of the Grade 5 Tswana learners in the fields Mathematics self-confidence and Attitude are statistically significantly better than those of the Tswana learners in Grades 3 and 4, while learners in Grade 5 also achieved statistically significantly better in Field 3 (Assistance) than did learners in Grade 3.

The Kruskal-Wallis procedure (Table 7) indicated significant differences between the medians of the three grade groups (i.e. Grades 3, 4 and 5) in respect of the following four subsections (Q2-Q5): Mental Arithmetic (where language plays a role), Mechanical Operations (where language plays a less important role than for example in Word Sums), Notation and Place value (where language plays a role), Word Sums (where language plays a role), as well as the Total Score (Q6) obtained in the diagnostic test (Mafikeng area).

Interestingly enough, and despite the findings in the previous paragraphs, the Grade 3 Tswana learners' medians in each of the subsections (Q2-Q5) and the Total Score (Q6) were significantly higher than the medians of the Grade 5 Tswana learners (Table 7). It has emerged inter alia from discussions with learners in Grade 3 that the Grade 3 Tswana-speaking learners (taking their grades into account) have a better knowledge of the language of mathematics. This factor subsequently has a positive impact on their performance in mathematics tests that require a good basic knowledge of the language of mathematics.

The medians of the Grade 4 Tswana learners in the subsection Mental Arithmetic (Q2 where language plays a role) are statistically significantly lower than the medians of Grades 3 and 5 learners (Table 7). The Tswana learners in Grade 4 experience more serious problems with Mental Arithmetic where mathematics language plays a role.

\section{Some 'concrete’ recommendations}

Our research makes it clear that Tswana learners' problems in mathematics may, inter alia, include the following assessment and evaluation methods:

- A mathematics portfolio for the establishment of a permanent record of the Tswana learners' comprehension of mathematical concepts.

- The use of diagnostic tests (such as the test referred to in this article) that are aimed at the assessment of the cognitive facets of the Tswana learners' mathematics performance.

- The introduction of questionnaires (such as the Learner Questionnaire referred to in this article) that have as aim the assessment of the affective facets of the Tswana learners' mathematics performance. 
- Co-operative learning may lead to greater self-confidence and boldness when working in groups.

- The use of worksheets in mathematics. A clearer exposition of questions may lead to more effective teaching.

An important item to be included in the portfolio is the diagnostic analysis or error analysis of the learners' work in formal, informal or standardised assessment. Diagnostic assessment has the following two broad aims:

- The identification of specific problem areas experienced by the learner in mathematics - cognitive as well as motor facets.

- Survey of the learners' mathematics habits and attitude with regard to mathematicsaffective and normative facets.

\section{Evaluation of cognitive facets}

The following tests/work of the learners may, inter alia, be used for diagnostic analysis:

- Informal diagnostic tests, specifically set by the teacher to test specific concepts or combinations of concepts. The diagnostic test (Mafikeng area) is an example of such a test.

- Standardised or formal diagnostic tests.

- Schoolbooks.

- Work assignments.

- All tests, examinations and other forms of assessment and evaluation.

\section{Evaluation of affective facets}

Affective facets that may be assessed, include, inter alia, the following:

- Visible facets: The learner's initiative, participation in class discussions and cooperation in a group context.

- Hidden facets: The learner's attitude and disposition towards mathematics as a subject; his/her self-confidence and perseverance.

- Taking the research results and views of the learners and teachers as well as the positive way in which all the research questions were answered into account, the main problems of the research may be remarked upon as follows: There seems to be a relationship between the Tswana learner's inadequate language proficiency and an inability to perform well in mathematics, as well as between his/her cognitive disposition and his/her mathematics achievement.

To address the challenge of inadequate performance in mathematics by the Tswana learner in the Mafikeng area effectively, a number of matters deserve our attention. Training of teachers for the teaching of mathematics language to the non-Englishspeaking learner seems essential, as well as facilitation of parental guidance programmes and programmes that may enable the parent to help the Tswana learner 
with mathematics at home. It is therefore essential that parents are empowered to become involved. Consideration should, for example, be given to the 'training' of a number of parents who may in turn 'train' other parents, and to in-service training of teachers of Tswana-speaking learners in the Mafikeng region in the teaching of mathematics.

Future research on the mathematics achievement of Tswana learners should also take into more detailed account the objectives of mathematics teaching. Attention should be given to the development of problem-solving skills, as well as to the development of conceptual knowledge and knowledge concerning procedures. A framework for mathematics teaching should be discussed, including the question about the ways in which learners learn mathematics. This involves, on the one hand, an investigation into the three cognitive processes that contribute to the construction of mathematical knowledge, namely presentations, reflection and automatisation and, on the other hand, an investigation into the way in which learners do, observe, abstract, make connections, draw conclusions and develop skills. The question of instruction strategies needs attention. Research designs should make provision for reference to relationalised thinking, inductive and deductive thinking, as well as cognitive modelling (thinking out aloud) as an instruction strategy. Haycock (2001) suggests that the achievement gap between the achievements of advantaged and disadvantaged students is partly caused by teachers in disadvantaged regions who not only give their students fewer assignments to do, but also by the fact that these assignments are of an inferior quality and then award high grades to work that deserves low grades. She goes on to say that disadvantaged students need extra help (including more time and instruction). Lastly, it is of crucial importance to appoint teachers who not only know how to teach subjects, but who have also mastered the subject content satisfactorily.

\section{Lastly: reflections on a more philosophical note}

The current study highlights the fact that language discourses much of what teachers practise in mathematics classes. Sentson (1994) links up with this view by pointing to the relationship between learners' proficiency in their first and second language: 'When mathematics is learned in a second language it is not only the learner's proficiency in this second language (L2) that affects the nature and quality of learning, but also the learner's proficiency in his/her first language (L1)' (p. 110).

Setati and Adler (2002, p. 265), after intensive research on code-switching in primary mathematics classrooms (a regular occurrence in South African classrooms), conclude that 'negotiating across languages is intertwined with negotiating across discourses'. In this way, indeed, learners' mother tongue may be utilised as a main learning resource (Setati \& Adler, 2002). Setati (2002, p. 19) aptly states that it would be short-sighted in these matters to focus only on the fact that second- or thirdlanguage learners in English study mathematics in a 'foreign' language, but, even more so, to take into account that 'various languages used will privilege different discourses in mathematics'. Clearly, this facet of teaching facilitation in Tswana classrooms needs to be investigated further. 
Sibaya, Sibaya and Mugisha (1996) refer to the relationship between language proficiency and achievement in mathematics in the following terms: 'Black secondary school pupils' performance in mathematics is significantly influenced by the command of the language of instruction. Furthermore, black pupils who have good command of mathematics language do better in mathematics than those who have poor command' (p. 36).

In Koen's (2003) research, Sesotho learners achieved a mean score of 36.1\% in the reading test, which suggests that these learners experience reading problems in their mother tongue. This is cause for concern, especially since international research has shown conclusively that learners need at least six to eight years' education in their mother tongue before a second or third language can be used successfully as a teaching medium (Koen, 2003).

On a more concrete level, Rothman and Cohen (1989) justifiably ask where the teaching of the 'language of mathematics' fits into the mathematics curriculum. These authors suggest that teachers need to apply themselves to the specific teaching of the language of mathematics, particularly in cases where mathematics is taught by means of a second or a third language. Joubert (1990) has found that mathematical reading proficiency can be developed and reports that the introduction of a reading programme aimed at promoting mathematical reading proficiency rendered an improvement of $14.16 \%$ in the next test. Any possible remedial strategy will therefore have to make provision for the specific teaching of mathematics language.

However, our study also makes it clear that mathematics teaching cannot be divorced from the socio-economic context in which it is taught. According to Ramnarain (2003), disadvantaged learners (especially those learners from seriously impoverished learning environments) lack a sound informal mathematics knowledge base and the skill to 'engage independently and effectively in mathematical tasks' (p. 33). Teachers in our research group confirmed this view and opined that factors such as a serious lack of parental involvement and a severely disadvantaged early learning environment potentially debilitate these learners for the rest of their lives. Ramnarain's findings assume particular significance in the light of the following findings. According to the Department of Education (DoE) (2003), approximately 31\% of households have access to commodities such as television, radio, phones, computers, books and magazines. Newspapers and magazines were in even shorter supply, with only 235 of the learners having access to these commodities. 25.5\% of learners indicated that they only had one meal per day. Recent research conducted by the DoE (2003) has shown conclusively that resources at home, followed by factors such as ease of access to school, parents' education level and early childhood development, have the strongest influence on learner achievement. The DoE (2003), in conclusion, emphasises that a strong (positive) correlation exists between learner achievement and the quality of learner support facilities at school.

Clearly it would be foolhardy to underestimate the interplay between the political (policy) context, currently adhered to pedagogical epistemologies and classroom matters (such as those spelt out above, e.g. the language of instruction). Let us explain. The current approach to education in South Africa, namely an OBE 
approach (embedded in the Curriculum 2005 policy) emphasises a learner-centred and learner-paced pedagogical approach, and aims at making learning more relevant to the daily lives of learners (DoE, 2003). This approach encourages parents and learners to make optimal use of learner support materials (resources) at home in the learning facilitation process. However, the twin problems of an inadequate home environment and a disadvantaged school environment combine to deny learners access to these resources, thereby negating, to a certain extent, the lofty ideals contained in the policy documents.

\section{References}

Child, D. (1990) The essentials of factor analysis (London, Holt, Rhinehart \& Winston).

Department of Education (DoE) (1995) The white paper on education and training. Government Gazette. Number 16312, March (Pretoria, Government).

Department of Education (DoE) (2003) Systemic evaluation: foundation phase, mainstream. National report (Pretoria, Government Printers).

Erasmus, P. (2002) Developing remedial strategy in mathematics for Tswana speaking learners. Unpublished MEd dissertation, University of Pretoria.

Haycock, K. (2001) Closing the achievement gap, Educational Leadership, 58(6), 6-11.

Howie, S. (2001) Mathematics and science performance in Grade 8 in South Africa (Pretoria, Human Sciences Research Council).

Joubert, G. J. (1990) Reading competency in mathematics, South African Fournal of Education, $10(1), 24-30$.

Kahn, M. (2004) For whom the school bell tolls: disparities in performance in senior certificate mathematics and physical science, Perpectives in Education, 22(1), 149-156.

Kassiem, A. (2004, May 26) Grade 6 pupils can't read or write-poll, Pretoria Newws, p. 2.

Koen, M. P. (2003) The design and evaluation of a reading and spelling programme for Sesotho speaking learners in grade 1. Unpublished doctoral thesis, Bloemfontein, University of the Free State.

Maree, J. G. (1997a) The development and evaluation of a study questionnaire in mathematics. Unpublished $\mathrm{PhD}$ thesis, University of Pretoria.

Maree, J. G. (1997b) Mamual for the Study Orientation Questionnaire in Mathematics (Pretoria, Human Sciences Research Council).

Ramnarain, U. (2003) A strategies-based problem solving approach in the development of mathematical thinking, Pythagoras, 57, 32-35.

Rothman, R. \& Cohen, J. (1989) The language of math needs to be taught, Academic Therapy, 25, 133-142.

Sentson, C. (1994) The effect of language of presentation on pupils' performance in a mathematics test, South African Fournal of Education, 14(3), 109-115.

Setati, M. (2002) Researching mathematics education and language in multilingual South Africa, The Mathematics Educator, 2(2), 6-21.

Setati, M. \& Adler, J. (2002) Between languages and discourses: language practices in primary multilingual mathematics classrooms in South Africa, Educational Studies in Mathematics, 43(3), 243-269.

Sibaya, P. T., Sibaya, D. \& Mugisha, R. X. (1996) Black secondary school pupils' problems with mathematical concepts, South African fournal of Education, 16(1), 32-37. 